\title{
Е.Ю. Сысоева
}

\section{РЕЧЕВАЯ АГРЕССИЯ ПЕДАГОГОВ: СУЩНОСТЬ, ПРИЧИНЫ, ВИДЫ, ПУТИ ПРЕОДОЛЕНИЯ}

(C) Сысоева Елена Юрьевна - кандидат педагогических наук, доцент, доцент кафедры теории и методики профессионального образования, Самарский национальный исследовательский университет имени академика С.П. Королева, 443086, Российская Федерация, г. Самара, Московское шоссе, 34.

E-mail: giperium@mail.ru. ORCID: https://orcid.org/0000-0003-1855-9462

\section{АННОТАЦИЯ}

Рост вербальной агрессии в педагогической среде является одной из самых острых проблем в практике педагогического общения. Проявление вербальной агрессии педагогом (осознаваемое или неосознаваемое) приводит к коммуникативному дисбалансу, служит деструктивной речевой моделью для подражания учащихся, негативно сказывается на ходе учебно-воспитательного процесса, психологическом здоровье самого педагога, ведет к невротизации личности учащегося. Проанализированы сущность, причины и механизмы возникновения вербальной агрессии педагогов, систематизированы способы проявления и последствия агрессии в педагогическом общении. Применяются методы: анализ и синтез тематической научной информации, результатов исследований специалистов в рассматриваемой области; обобщение и систематизация фактов и положений; педагогическое наблюдение за речевой практикой педагогов. Выявлены основные виды речевой педагогической агрессии: категорические требования, намерение наказать, запрещение, выражение оценки в виде насмешки, ироничного замечания, явная или скрытая угроза, порицание, враждебное замечание. Обосновывается необходимость внедрения практико-ориентированной системы совершенствования коммуникативной компетентности педагога, направленной на гармонизацию педагогического общения через освоение конкретных способов и приемов нейтрализации вербальной агрессии. Определены средства развития коммуникативного потенциала педагога: расширение представлений о возможных средствах достижения коммуникативного равновесия в педагогическом общении путем освоения техник партнерского взаимодействия; систематизация представлений об эффективных средствах речевого воздействия; актуализация рефлексивных умений педагога в острых, конфликтных ситуациях; развитие навыков конструктивной критики.

Ключевые слова: речевая агрессия, виды речевой агрессии педагогов, коммуникативная компетентность, техники партнерского взаимодействия.

Цитирование. Сысоева Е.Ю. Речевая агрессия педагогов: сущность, причины, виды, пути преодоления // Вестник Самарского университета. История, педагогика, филология. 2018. Т. 24. № 4. C. 48-53. DOI: http://doi.org/10.18287/2542-0445-2018-24-4-48-53.

This is an open access article distributed under the Creative Commons Attribution License Which permits unrestricted use, distribution, and reproduction in any medium, provided the original work is properly cited. (CC BY 4.0) 


\title{
TEACHERS' VERBAL AGGRESSION: ITS CORE, REASONS, TYPES, WAYS TO COUNTERACT
}

\author{
(C) Sysoeva Elena Yurievna - Candidate of Pedagogical Sciences, associate professor, assisstant professor of the \\ Department of Theory and Methods of Professional Education, Samara National Research University, 34, \\ Moskovskoye shosse, Samara, 443086, Russian Federation. \\ E-mail: giperium@mail.ru. ORCID: https://orcid.org/0000-0003-1855-9462
}

\section{ABSTRACT}

The increase in acts of verbal aggression in pedagogical environment is one of the main issues of pedagogical communication. Teachers' verbal aggression (conscious or nonconscious) leads to communicative instability and becomes a destructive speech model for students to emulate, so that has a negative impact on educational process, teacher's psychic health and causes students' neurotization. The article analyzes the core of teachers' verbal aggression, its reasons and mechanisms; organizes its types and effects in pedagogical communication. Methodology: analysis and synthesis of specific scientific knowledge; generalization and systematization of facts and statements; pedagogical observation on teachers' verbal aggression in practice. The study identifies the main types of teachers' verbal aggression: imperative request, intention to punish, interdiction, mockery as a way of assessment, ironic comments, clear or hidden thread, censure, hostile comments. The author proves the necessity to implement a practical-oriented system of teachers' communicative competence development aimed to harmonize pedagogical communication through certain ways and methods to counteract verbal aggression. The article defines the means to develop teacher's communicative potential: to improve the knowledge how to reach communicative balance in pedagogical communication with the suitable partnership strategies; to investigate the understanding of linguistic manipulation and its impact; to update teacher's reflective abilities in situations of heated conflict; to develop skills in useful criticism.

Key words: verbal aggression, types of teachers' verbal aggression, communicative competence, partnership strategies

Цитирование. Sysoeva E.Yu. Rechevaia agressiia pedagogov: sushchnost', prichiny, vidy, puti preodoleniia [Teachers' verbal aggression: its core, reasons, types, ways to counteract]. Vestnik Samarskogo universiteta. Istoriia, pedagogika, filologiia [Vestnik of Samara University. History, pedagogics, philology], 2018, Vol. 24, no. 4, pp. 48-53. DOI: http://doi.org/10.18287/2542-0445-2018-24-4-48-53.

\section{Введение}

Речь для педагога является основным профессиональным компонентом и средством обучения и воспитания, а также образцом, сознательно или бессознательно усваиваемым, в той или иной мере воспринимаемым и неизбежно «тиражируемым» учениками. Особое внимание к уровню коммуникативной компетентности педагога, его речевой подготовке вызвано заметным падением общего уровня речевой культуры в российском обществе, которое обусловлено как общей либерализацией ценностей, идеологическим вакуумом, трансляцией моделей агрессивного поведения в СМИ, так и процессом непрерывного реформирования образования на протяжении последней четверти века. У многих педагогов в ситуации пермаментной неопределенности происходит инверсия смысла педагогической деятельности, снижается чувство значимости и ответственности за свои речевые действия. Рост вербальной агрессии является серьезной проблемой современного общества, однако наибольшую опасность, по мнению исследователей
(Е.П. Ильина, Л.М. Митиной, М.Ю. Олешкова, К.Ф. Седова, В.А. Сонина, Ю.В. Щербининой и др.), представляет речевая агрессия педагогов. Именно она нарушает гармонию речевого общения в ученическом коллективе, служит деструктивной речевой моделью для подражания учащихся, негативно сказывается на их эмоциональнопсихологическом состоянии, способствуя невротизации, размывает этические границы в коммуникации.

\section{Степень разработанности проблемы}

Исследователи по-разному трактуют феномен речевой агрессии: как «сферу речевого поведения, которая мотивирована агрессивным состоянием говорящего» [Енина 2000], как «вербальное выражение отрицательных эмоций, чувств или намерений в неприемлемой в данной речевой ситуации форме» [Щербинина 2001]. Исследователь Ю.В. Щербинина включает в определение словосочетание «речевая ситуация», поскольку классифицировать слова говорящего как вербальную агрессию можно 
только в контексте. Одна и та же реплика, произнесенная в разных речевых ситуациях, может восприниматься по-разному. Таким образом, вербальную агрессию следует рассматривать с позиций разнообразных речевых ситуаций, что объясняется неоднородностью мотивационной сферы участников общения, ситуациями проявления, а также формами вербального воплощения, целями, которые реализуют коммуниканты, и другими факторами. Интересен подход к трактовке понятия «речевой агрессии» А.К. Михальской, которая определяет данный феномен как «установку на антидиалог, поскольку данный тип поведения основан на сознательной ориентации адресанта на субъектнообъектный тип отношений» [Михальская 2015].

Речевая агрессия подразделяется на осознанную и неосознанную. Из названий этих форм следует, что при неосознанной вербальной агрессии говорящий не ставит перед собой цели обидеть или оскорбить адресата, соответственно, осознанной речевая агрессия будет в том случае, если говорящий намеренно использует в речи грубые, оскорбительные и прочие языковые средства. Неосознаваемость педагогом вербальной агрессии является серьезным барьером на пути ее искоренения. В сознании педагога происходит подмена понятий: речевая агрессия воспринимается как эмоциональная несдержанность, резкость.

Неосознанная речевая агрессия подразделяется на два вида: компенсаторную и игнорантную. Компенсаторная агрессия «выражается в замене реальных действий речевыми, предполагающими при этом возможную субституцию объекта агрессии» [Громова 2016]. Носитель языка нарушает нормы коммуникативного поведения в виду излишнего эмоционального возбуждения. Он не контролирует свою речь, при этом не желая причинить вред адресату и даже не предполагая, что это может произойти. Речевая агрессия выступает как способ психологической разрядки, самозащиты или установления коммуникативного барьера. Игнорантную форму речевой агрессии говорящий проявляет по причине низкого уровня грамотности, владения языком. Чаще всего педагоги неосознанно используют агрессивную лексику, они не ставят цели унизить или оскорбить учащегося, но последствия подобного общения могут быть очень серьезными. Рассмотрим причины агрессии в речи педагогов. Исследователи выделяют социальные, психологические и собственно коммуникативные причины проявления вербальной агрессии, в том числе педагогов.

С точки зрения психологии педагогического труда частой причиной речевой агрессии являются негативные личностные качества самого педагога: непроработанная (неосознаваемая) властность, желание самоутвердиться за счет воспитанника, неразвитость профессионального самосознания, отсутствие профессионально важных качеств: саморегуляции, эмоциональной, интеллектуальной гибкости. Неспособность педагога выдерживать высо- кие интеллектуальные, эмоционально-коммуникативные нагрузки приводит к эмоциональным срывам, деперсонализации и выгоранию. Кроме того, со временем мышление педагога становится стереотипизированным, повышается авторитарность в поведении и общении, наблюдается неприятие отличного от собственного мнения. Названные причины детерминируют проявления компенсаторной речевой агрессии. С увеличением стажа профессиональной деятельности и возрастом педагогов усиливается проявление агрессии в зависимости от эмоционального состояния, инициируемого обидой, чувством неудовлетворенности собой и своим профессиональным статусом. Стремление педагога занять доминирующую позицию подкрепляется вербально. Анализ корреляционных связей и описательных статистик свидетельствуют о сложной зависимости вербальной агрессии от эмоциональной стабильности педагога, для которого наиболее характерны высокая чувствительность, ранимость и обидчивость [Ильин 2014] .

Источником возникновения агрессивного поведения педагога является ситуация (конфликтная или фрустрирующая), играющая роль внешнего стимула (непослушание учащихся на уроке, невыполнение заданий педагога, нарушение школьных правил поведения, создание каких-либо препятствий в учебной деятельности, несогласие и различного рода угрозы со стороны администрации, коллег, учащихся, родителей). Важным моментом является осознание данной ситуации, придание ей личностной значимости и переход в конфликт или фрустрацию. Таким образом, вербальная агрессия педагога становится механизмом психологической защиты в момент острых педагогических ситуаций, когда в поведенческом репертуаре педагога не хватает целесообразно-приемлемых форм отражения и гармонизации взаимодействия, педагог испытывает определенный «дефицит поведения». Скудный словарный запас - коммуникативная причина проявления вербальной агрессии. Педагог зачастую не может подобрать нужных слов для выражения недовольства или поддержания дисциплины, поэтому от учителя нередко можно услышать агрессивную лексику. Таким образом проявляется игнорантная языковая агрессия.

Анализ речевых педагогических ситуаций, в которых ярко запечатлеваются профессионально-педагогический облик и стиль деятельности учителя, высвечивает особенности его профессионального менталитета: властность и авторитарность, постоянную центрацию на своем Я, многие маскировочные тенденции в поведенческих актах. Агрессивная речь учителя подавляет личность ученика, приводя к негативным последствиям: у учащихся снижается самооценка, возникает неуверенность в себе, появляется сначала страх перед конкретным педагогом, а потом перед учебной деятельностью.

Ю.В. Щербинина выявила, что в школьной среде речевая агрессия педагогов выражается в пренебрежительно-грубом или повелительно-покровитель- 
ственном отношении к ученикам, повышении тона, резких восклицаниях, неоправданно частом употреблении повелительного наклонения глаголов, отсутствии необходимых формул речевого этикета, грубых замечаниях и язвительных насмешках. Из 80 распоряжений только шесть отдаются со словом «пожалуйста» [Сонин 2007]. М.Ю. Олешков в проявлении прямой вербальной агрессии выделил четыре тематические группы: грубые выражения волеизъявления: категорические требования («Заткнитесь»!), намерение наказать («Я тебя сейчас убью, Петров», запрещение; выражение оценки в виде насмешки, ироничного замечания («Вы что, больной, что ли?»); угроза с прямым указанием на последствия в случае невыполнения требования («Если кто откроет рот, поставлю два!») или скрытая («Сообщения должны отскакивать от зубов»); агрессивные высказывания, не имеющие строгой видовой отнесенности, по преимуществу гневные («Ты испытываешь мое терпение»!). Кроме того, в силу оценочности педагогической деятельности педагоги склонны к таким видам вербальной агрессии, как: враждебные замечания, порицание и ирония. В замечании может быть выражена отрицательная позиция к коммуниканту («Тебя слушать тошно!», «Как же ты мне надоел!») [Олешков 2005]. Порицание, являясь выражением неодобрения, осуждения, структурно состоит из обращения к адресату (обычно «ты», реже - «вы»), с использованием оценочных слов («Порядочные люди так не поступают!»). Ирония, колкость - это обидные шутки в чей-либо адрес с целью подвергнуть данное лицо осмеянию («Твоей иголкой только трупы зашивать!»). Колкость предполагает особую речевую изощренность и очень часто строится на подтексте или ироническом несовпадении сказанного с реальным [Новикова, Смирнов 2018, с. 198]. Иногда ирония педагога перерастает в этически неприемлемые формы сверх-обобщений, которые не имеют конкретного адресного характера, носят дегуманистический, сексистский характер, являются свидетельством непроработанности личностных проблем: «Женщина-заготовка человека», «Женщина сосуд удовольствий». Используя подобную иронию, педагог не только нарушает коммуникативное равновесие, определенный баланс отношений между собой и объектом ироничного высказывания, задевая чувство достоинства учащегося, но и нарушает этические нормы коммуникации. Опыт собственных наблюдений за речевыми действиями педагогов позволяет сделать неутешительный вывод о том, что иронию многие педагоги не воспринимает как вид вербальной агрессии, считают эффективным средством речевого воздействия.

Опасность речевой педагогической агрессии заключается в том, что она становится источником проявления речевой агрессии учащихся в связи с их склонностью и повышенным стремлением к подражанию и копированию агрессивных речевых действий. Добиваясь видимости послушания, поддержания дисциплины на уроке, педагог невольно вырабатывает у учащихся ответную агрессивную реакцию. При этом не учитывается, во-первых, создание негативного отношения к самому агрессору, которое затем переносится на все «представляемое» педагогом сообщество, во-вторых неадекватное восприятие учащимся агрессивных речевых действий педагога. У учащихся складывается мнение, что агрессия педагога направлена не на их поведение в данной речевой ситуации, а на них самих, на их личность. Вербальная агрессия создает негативную модель поведения человека в целом и тем самым является основой социально неприемлемого поведения - агрессии физической. Любые проявления вербальной агрессии, особенно в форме враждебных реакций, препятствуют реализации основных задач эффективного речевого общения: затрудняют полноценный обмен информацией, тормозят восприятие и понимание собеседниками друг друга, снижают чувство психологической безопасности. В связи с этим В.А. Сонин подчеркивает, что антогонизм между учителем и учеником имеет социальные последствия: воспитывается пассивный к социальным проблемам человек, не способный к самоорганизации, инициативе, самостоятельности, критическому мышлению [Сонин 2007].

\section{Результаты исследования}

Одним из способов решения данной проблемы, на наш взгляд, является внедрение в систему повышения квалификации практико-ориентированного курса, направленного на формирование коммуникативной компетентности педагога, в основе которого лежит освоение конкретных способов преодоления вербальной агрессии. Под коммуникативной компетентностью вслед за Ю.Н. Емельяновым будем понимать совокупность коммуникативных способностей, коммуникативных умений и коммуникативных знаний, адекватных коммуникативным задачам и достаточных для их решения [Емельянов 1995]. Многие ученые единодушно отмечают, что коммуникативная компетентность педагога не сводима к обобщенному способу действия и не может быть сформирована как отдельный навык или умение: она формируется интегративно в результате личного опыта действия как индивидуализированная способность к эффективному общению в профессии. Для активизации процесса совершенствования коммуникативных умений и навыков педагога необходим учебный процесс, в котором имеет место совместная в системе «Педагог-педагог» рефлексия приобретенных коммуникативных знаний, организован опыт решения поставленных коммуникативных задач, направленных на овладение новыми способами практического педагогического мышления, активизирован коллективный поиск новых моделей адекватного речевого поведения, снижающих конфликтогенность учебно-воспитательного процесса, уровень эмоционального напряжения его субъектов, а значит, и возможных проявлений речевой агрессии. 
Одной из главных задач формирования коммуникативных умений считаем развитие и корректировку гуманистической направленности личности педагога, умения принимать личность учащегося во всем многообразии индивидуальных проявлений, создавать условия для развития его коммуникативного потенциала. Актуализация личностносмыслового начала педагогической деятельности, рефлексия личного и профессионального опыта, положительных и отрицательных сторон своей коммуникативной деятельности становится отправной точкой поиска и обнаружения коммуникативноэтического идеала во взаимодействии с учащимся. Развитие рефлексивного опыта педагога предполагает соблюдение ряда психолого-педагогических условий: развивать у слушателей умение приостановить собственную деятельность и «встать» над собственной деятельностью, развивать умения выделять главные моменты своей и чужой деятельности как целого; развивать умение объективировать деятельность, то есть переводить с языка непосредственных впечатлений и представлений на язык общих положений, принципов и схем [Колесникова 2007]. Содержание процесса развития коммуникативных навыков педагогов предполагает включение информационных блоков о сущности и специфике педагогической коммуникации, о личностной (визуальной, кинестетической, ольфакторной) стороне эффективного коммуникативного имиджа; о причинах, сущности, видах, последствиях речевой агрессии в педагогической деятельности; об основных принципах бесконфликтного общения и способах нейтрализации конфликтогенов; об этапах и техниках партнерского взаимодействия [Руднева, Стрекалова, Соловова, Сысоева, Санько, Никулина 2016]. Партнерским, или субъект-субъектным, общением является такое, при котором учитываются интересы других участников взаимодействия, а также их чувства, эмоции, переживания, признается ценность личности другого человека [Сидоренко 2008]. Признание значимости эмоционального компонента в профессионально-педагогическом общении предполагает обязательное, сознательное управление эмоциональным состоянием (своим и партнера), развитые умения использования силы положительных эмоций для оптимизации учебно-воспитательного процесса.

Овладение педагогами конкретными техниками партнерского взаимодействия, которые направлены на снижение уровня эмоционального напряжения и способствуют гармонизации психологического климата в аудитории, является важнейшей задачей профилактики вербальной педагогической агрессии. Среди техник партнерского взаимодействия психологи выделяют: техники активного слушания (расспрашивание, цитирование, перефразирование, резюмирование), техники снижения эмоционального напряжения: отражение чувств партнера, подчеркивание общности с партнером, метафорическая вербализация, способствующая нейтрализации негативных чувств, подчеркивание значи- мости партнера, эвфемизация, различные виды благодарности(прямой и косвенной), техники позитивного переформулирования, техники конструктивной критики, позитивные оценочные высказывания относительно действий партнера. Освоение техник «возвышения» партнера считаем важным элементом в развитии фасилитативной функции педагогического общения, направленной на поддержание позитивной Я-концепции учащегося и создание условий помогающих отношений.

Динамика развития коммуникативных умений и навыков педагога определяется отказом от авторитарно-манипулятивного стиля коммуникативной деятельности, заменой ролевого взаимодействия на межличностное, освоением позиции партнерства, сотрудничества, гармонизацией и усложнением компонентов педагогической деятельности. Педагог с высоким уровнем коммуникативной компетентности осознает собственную педагогическую уникальность, рассматривает педагогическое общение как пространство проявления коммуникативной креативности, находится в постоянном поиске речевых средств, гармонизирующих педагогическую реальность, в которой развиваются субъекты образовательного процесса, создает условия для раскрытия личностного и коммуникативного потенциала учащегося.

\section{Библиографический список}

Громова 2016 - Громова Н.С. Речевая агрессия: от коммуникативных ошибок до правонарушений // Юрислингвистика. 2016. №5. C. 173-189. URL: https:// cyberleninka.ru/article/n/rechevaya-agressiya-otkommunikativnyh-oshibok-do-pravonarusheniy.

Емельянов 1995 - Емельянов Ю.Н. Теория формирования и практика совершенствования коммуникативной компетентности. М.: Просвещение, 1995. 183 c.

Енина 2000 - Енина Л.В. Речевая агрессия и речевая толерантность в средствах массовой информации [Электронный ресурс] // Российская пресса в поликультурном обществе: толерантность и мультикультурализм как ориентиры профессионального поведения (Материалы исследований и научнопрактической конференции). M., 2000. URL: http:// www.tolerance.ru/RP-rech-agress.php?PrPage=Multi (дата обращения: 02.05.2018).

Ильин 2014 - Ильин Е.П. Психология агрессивного поведения. СПб.: Питер, 2014. 368 с.

Колесникова 2007 - Колесникова И.А. Коммуникативная деятельность педагога: учеб. пособие для студ. высш. пед. учеб. Заведений / под ред. В.А. Сластенина. М.: Издательский центр «Академия», 2007. $336 \mathrm{c}$.

Михальская 2015 - Михальская А.К. Педагогическая риторика: учебное пособие. Ростов н/Д.: Феникс, 2015. $379 \mathrm{c}$.

Новикова, Смирнов 2018 - Новикова Т.Ф., Смирнов Т.Ю. Приемы нейтрализации вербальной агрессии в составе средств речевого воздействия // Научные ведомости Белгородского государственного университета. Серия: 
Гуманитарные науки. 2018. Т. 37. № 2. C. 194-203. DOI: 10.18413/2075-4574-2018-37-2-194-203. URL: https:// elibrary.ru/item.asp?id=35128428.

Олешков 2005 - Олешков М.Ю. Вербальная агрессия учителя в процессе педагогического общения // Стандарты и мониторинг в образовании. 2005. № 2. C. 43-50. URL: http://pedlib.ru/Books/3/0327/ 3-0327-1.shtml.

Руднева, Стрекалова, Соловова, Сысоева, Санько, Никулина 2016 - Руднева Т.И., Стрекалова Н.Б., Соловова Н.В., Сысоева Е.Ю., Санько А.М., Никулина И.В. Педагогическое сопровождение инновационной педагогической деятельности // Вестник Самарского университета. История, педагогика, филология. 2016. № 3.1. C. 50-57. URL: http:// journals.ssau.ru/index.php/hpp/article/view/4278.

Сонин 2007 - Сонин В.А. Учитель как социальный тип личности. СПб: Речь, 2007. 400 с.

Сидоренко 2008 - Сидоренко Е.В. Тренинг коммуникативной компетентности в деловом взаимодействии. СПб.: Речь, 2008. 208 с.

Щербинина 2001 - Щербинина Ю.В. Вербальная агрессия в школьной речевой среде: автореф. дис. ... канд. пед. наук. М., 2001. 16 с.

\section{References}

Gromova 2016 - Gromova N.S. Rechevaia agressiia: ot kommunikativnykh oshibok do pravonarushenii [Speech aggression: from communicative errors to legal offenses]. Iurislingvistika [Legal Linguistics], 2016, no. 5, pp. 173189. Available at: https://cyberleninka.ru/article/n/ rechevaya-agressiya-ot-kommunikativnyh-oshibok-dopravonarusheniy [in Russian].

Emelyanov 1995 - Emelyanov Yu.N. Teoriia formirovaniia $i$ praktika sovershenstvovaniia kommunikativnoi kompetentnosti [Theory of formation and practice of improving communicative competence]. M.: Prosveshchenie, 1995, 183 p. [in Russian].

Enina 2000 - Enina L.V. Rechevaia agressiia i rechevaia tolerantnost' $v$ sredstvakh massovoi informatsii [Elektronnyi resurs] [Speech aggression and speech tolerance in the mass media [Electronic resource]]. In: Rossiiskaia pressa $v$ polikul'turnom obshchestve: tolerantnost' $i$ mul'tikul'turalizm kak orientiry professional'nogo povedeniia (Materialy issledovanii i nauchno-prakticheskoi konferentsii) [Russian press in a multicultural society: tolerance and multiculturalism as guidelines for professional behavior (Materials of research and research and practical conference)]. M., 2000. Available at: http:// www.tolerance.ru/RP-rech-agress.php?PrPage $=$ Multi (accessed: 02.05.2018)[in Russian].
Il'in 2014 - Il'in E.P. Psikhologiia agressivnogo povedeniia [Psychology of aggressive behavior]. SPb.: Piter, 2014, 368 p. [in Russian].

Kolesnikova 2007 - Kolesnikova I.A. Kommunikativnaia deiatel'nost' pedagoga: ucheb. posobie dlia stud. vyssh. ped. ucheb. zavedenii. I.A. Kolesnikova; pod red. V.A. Slastenina [Communicative activities of a teacher: textbook for university students. V.A. Slastenin (Ed.)]. M.: Izdatel'skii tsentr «Akademiia», 2007, 336 p. [in Russian].

Mikhalskaya 2015 - Mikhalskaya A.K. Pedagogicheskaia ritorika: uchebnoe posobie [Pedagogical rhetoric: tutorial]. Rostov-on-Don: Feniks, 2015, 379 p. [in Russian].

Novikova, Smirnov 2018 - Novikova T.F., Smirnov T.Yu. Priemy neitralizatsii verbal'noi agressii $v$ sostave sredstv rechevogo vozdeistviia [Techniques of neutralization of verbal aggression as part of the tools of speech influence]. Nauchnye vedomosti Belgorodskogo gosudarstvennogo universiteta. Seriia: Gumanitarnye nauki [Belgorod State University Scientific Bulletin. Humanities], 2018, Vol. 37, no. 2, pp. 194-203. DOI: 10.18413/2075-4574-2018-37-2-194203. Available at: https://elibrary.ru/item.asp?id $=35128428$ [in Russian].

Oleshkov 2005 - Oleshkov M.Yu. Verbal'naia agressiia uchitelia $v$ protsesse pedagogicheskogo obshcheniia [Verbal aggression of the teacher in the process of pedagogical communication]. Standarty i monitoring $v$ obrazovanii [Standards and Monitoring in Education], 2005, no. 2, pp. 43-50. Available at: http://pedlib.ru/Books/3/0327/30327-1.shtml [in Russian]

Rudneva, Strekalova, Solovova, Sysoeva, Sanko, Nikulina, 2016 - Rudneva T.I., Strekalova N.B., Solovova N.V., Sysoeva E.Yu., Sanko A.M., Nikulina I.V. Pedagogicheskoe soprovozhdenie innovatsionnoi pedagogicheskoi deiatel'nosti [Pedagogical support of innovative pedagogical activity]. Vestnik Samarskogo universiteta. Istoriia, pedagogika, filologiia [Vestnik of Samara University. History, pedagogy, philology], 2016, no. 3.1, pp. 50-57. Available at: http://journals.ssau.ru/ index.php/hpp/article/view/4278 [in Russian].

Sonin 2007 - Sonin V.A. Uchitel' kak sotsial'nyi tip lichnosti [Teacher as a social type of personality]. SPb.: Rech', 2007, 400 p. [in Russian].

Sidorenko 2008 - Sidorenko E.V. Trening kommunikativnoi kompetentnosti $V$ delovom vzaimodeistvii [Training of communicative competence in business interaction]. SPb.: Rech', 2008, 208 p. [in Russian].

Shcherbinina 2001 - Shcherbinina Yu.V. Verbal'naia agressiia $v$ shkol'noi rechevoi srede: avtoref. dis. ... kand. ped. nauk [Verbal aggression in the school speech environment; author's abstract of thesis Candidate's of Pedagogical Sciences thesis]. M., 2001, 16 p. [in Russian]. 